\title{
COMPARATIVE ANALYSIS OF SPATIAL STRESS IN THE JOINT ZONE OF TOWER PIER UNDER DIFFERENT SYSTEMS OF CABLE-STAYED BRIDGE
}

\author{
Long Liu' ${ }^{1}$ Yingying $B i^{2}$ \\ 1. Anyang Institute of Technology, the west end of Huanghe Avenue, Anyang \\ 455000,China;20160913@ayit.edu.cn \\ 2. Anyang Institute, 599 Zhonghua Road, South Section, Anyang 455000, China; \\ 1586743384@qq.com
}

\begin{abstract}
To explore the stress of the tower-beam-pier joint zone of a cable-stayed bridge under different systems, the submodel method in the finite element software ABAQUS was used to establish the local model of the tower-beam-pier joint zone of the bridge. At the same time, Midas/Civil was used to establish the rod system finite element model of the whole bridge. The correctness of the local model was verified by comparing the results of the finite element model and the local model. Then, by changing the combination mode of tower beam pier, the stress comparison analysis of the joint zone of the tower-beam-pier under different systems was carried out. The results showed the stress distribution of the semi-floating system which had no tensile stress at the pier top was more reasonable than that of the rigid frame system and the consolidation system. In the use of three different systems, there was concentrated tensile stress at the chamfer of the web and the bottom plate, where the steel bars should be added. In the rigid frame system, deflection of the main beam under load was the smallest, and the maximum displacement occurred at the boundary section, with the value of only $2.668 \mathrm{~mm}$.
\end{abstract}

\section{KEYWORDS}

Cable-stayed bridge, Joint zone of tower-beam-pier, Stress analysis, Semi-floating system, Rigid frame system, Tower-beam consolidation system

\section{INTRODUCTION}

The joint zone of tower-beam-pier is an important node of cable-stayed bridge, presenting a complex three-dimensional force state, which is a blind zone for stress calculation by the finite element method of rod system. The spatial stress analysis by solid finite element method can provide a basis for the improvement of the stress state of this position.

According to the combination mode of tower-beam-pier, cable-stayed bridge can be divided into floating system, semi-floating system, tower-beam consolidated system and rigid frame system. Scholars have carried out research on the stress condition of the tower-beam-pier joint zone of various systems of cable-stayed bridges. Yu Yanxia [1] made a comparative study on the parameters of the bridge system, and the results showed the consolidation system of tower-beampier was suitable for the connection form of cable-stayed bridges because of its large stiffness and small shrinkage. Wen Wangqing [2] compared and analyzed the influence of four systems on stiffness, temperature effect and structural force of three-span cable-stayed bridge. Pan Xiangwen [3] compared the mechanical properties of cable-stayed bridge under load by changing the system and different structural parameters, and found the combined system of tower-beam consolidation 


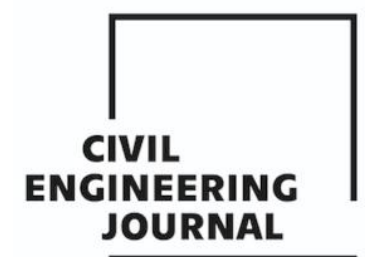

Article no. 54

THE CIVIL ENGINEERING JOURNAL 3-2021

and rigid frame had a larger stiffness. Deng Jiangtao [4] and Long Peiheng [5] established the tower-beam-pier joint zone model of rigid-frame cable-stayed bridge by using finite element software to analyze its spatial stress. Yu Lusong [6] studied the stress effect of prestressed beams of semi-floating cable-stayed bridges on the consolidated parts. Song Jun [7] made a study on stress state of the consolidation position of tower-pier of rigid frame system under four different working conditions with the submodel method. Through literature investigation, it is found that scholars had carried out research on spatial stress analysis of the tower girder pier joint zone in structural systems, but there is no report on the comparative stress analysis of tower-beam-pier joint zone under different systems of cable-stayed bridges.

To explore spatial stress of tower-beam-pier in the joint zone of cable-stayed bridge, several methods are commonly used, such as scale model test, photoelastic test, analytical calculation and finite element analysis. Hu Yuliu [8] used method of scaled model test to study parameters such as stress and displacement in the consolidation zone of tower-beam-pier in the using stage. Wang Ziwen [9] studied static performance of the tower-girder joint zone of singletower cable-stayed bridge with consolidation of tower-girder piers with method of scale model test and finite element method. Shang Guanping [10] analyzed the stress of cable-stayed bridge with beam-pier consolidation system with method of finite element and photoelastic test comparison. Dai Gonglian [11] studied the stress of the consolidation model of tower-beam-pier of a trussingsection cable-stayed bridge by combining model test with numerical simulation. Among these methods, the test cost of scale model is higher; the calculation accuracy of analytical method is poor; the calculation result of finite element is accurate and the cost is low.

Zhou Min [12] established the overall and local models of cable-stayed bridges respectively by adopting Midas/Civil and ANSYS finite element software, who also simulated and analysed the stress of the tower-pier consolidation zone. Li Bo [13] established the integral finite element model of cable-stayed bridge and the solid model of 0\# block respectively, and made a study on the spatial stress of $0 \#$ block under the most unfavourable load.

In this paper, the overall finite element model of cable-stayed bridge was established with the Midas/Civil software, and the local solid model of the tower-beam-pier joint zone of the cablestayed bridge was established by using ABAQUS software. The accuracy of the local solid model was verified by comparison of the results, and on this basis, the stress comparison analysis of the tower-beam-pier joint zone with different anchorage forms was carried out. The influence of anchoring on the force of cable-stayed bridge was discussed.

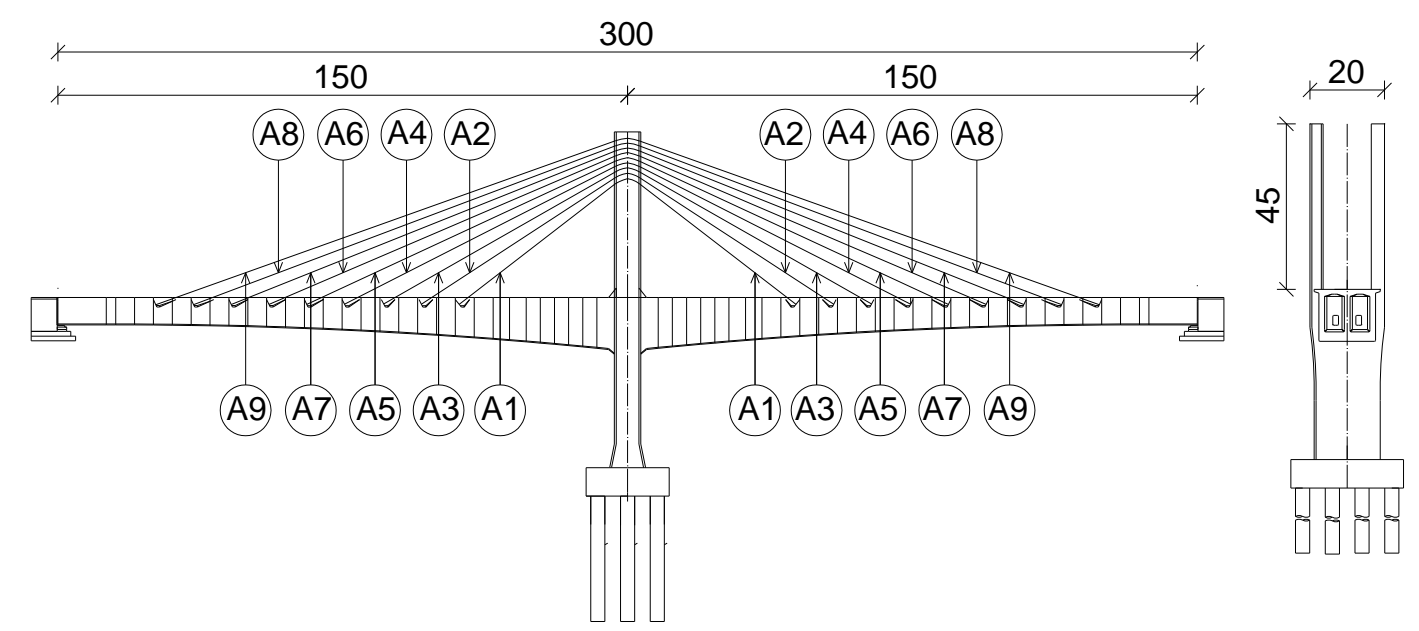

(a) Elevation

(b) Cross-section

Fig. 1 - Schematic diagram of cable-stayed bridge layout (unit: $m$ ) 


\section{NUMERICAL SIMULATION MODEL OF TOWER-BEAM-PIER JOINT ZONE}

\section{(1) Project overview}

A cable-stayed bridge with a span arrangement of $(150+150) \mathrm{m}$ adopted rigid frame system, which means the tower, beam and piers are consolidated. The main beam adopted the single-box double-chamber reinforced concrete box, with a total width of $20 \mathrm{~m}$ at top of the beam and a quadratic parabolic change in beam height. The stay cables adopted symmetrical space with double cable planes, with 18 cables. The cable tower adopted rectangular section and height of the tower was $45 \mathrm{~m}$. The overall layout of the bridge is shown in Figure 1.

\section{(2) The establishment of calculation model}

The finite element software ABAQUS was used to establish the local model of the towerbeam-pier joint zone of the cable-stayed bridge, as shown in Figure 2. The submodel method was adopted [14], and the whole model provided boundary conditions for the local model. To avoid the influence of boundary conditions on force of the joint zone, enough length of the main girder should be cut off. In the local model, the transverse bridge direction was the full width of the main beam, which was symmetrical along the bridge direction to the middle line of the bridge. The local corner of the chamfering section of the box girder at the end of the beam was C3D10 element, and the rest section was C3D8R element. There were 76007 elements in the model. Midas/Civil was used to establish finite element rod system model of the full bridge, and length of the intercepted main beam in tower beam pier joint zone was $31 \mathrm{~m}$, as shown in Figure 3. There were 228 nodes and 188 cells in the model.

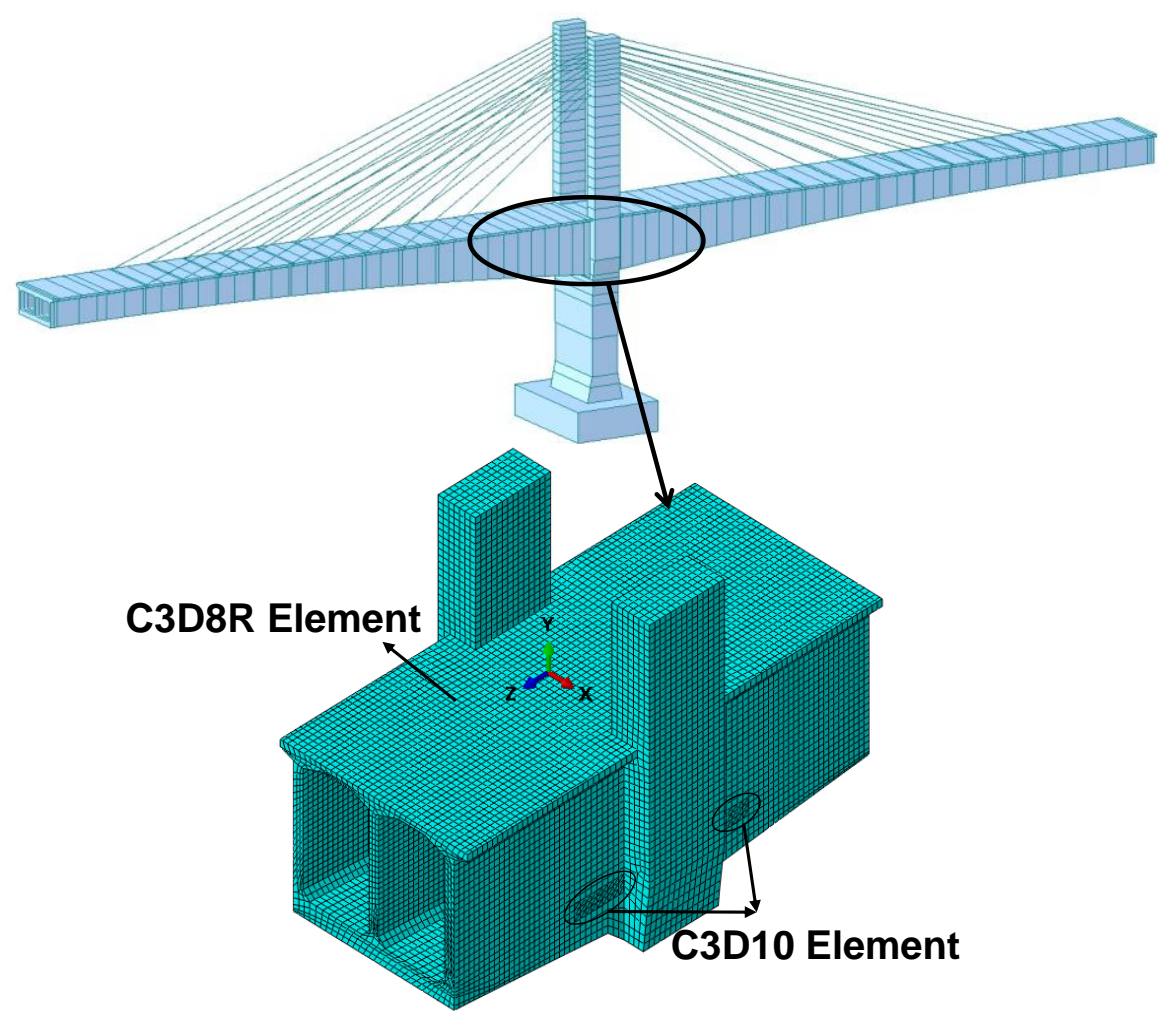

Fig. 2 - Finite element model

\section{(3) Calculation Parameters}

In the local model of the tower-beam-pier joint zone, ABAQUS internal constraints were used to couple the steel bundle node with the nearby concrete node, to consider internaction of the 
prestressed steel bundles and concrete, and the prestress was simulated by using cooling method [14]. There were 12 web bundles and 6 roof bundles in the consolidation zone, and both ends of the remaining steel bundles were all truncated at the boundary of the model. The prestress effect of truncated prestressed steel bundles was considered in the boundary force. There were 8 tendons of prestressed steel anchored to roof of the beam and 6 tendons of prestressed steel anchored to bottom of the beam. The specifications of tendons were 19-15.2 steel strands. The elastic modulus of prestressed steel bundle was $1.95 \times 10^{5} \mathrm{MPa}$, the bulk density was $78.5 \mathrm{kN} / \mathrm{m}^{3}$, and linear expansion coefficient was $1.2 \times 10^{-5}$. The stress of steel bundle was the effective prestress after considering prestress loss. The box girder and bridge tower were made of C60 concrete with an elastic modulus of $3.6 \times 10^{4} \mathrm{MPa}$.

\section{(4) Constitutive model of concrete}

In ABAQUS, the commonly used constitutive relations of concrete are wired elastic model, elastoplastic model and nonlinear elastic model. The purpose of this paper is to study the spatial stress distribution in joint zone of tower girder pier. Considering that no cracks occurred in the concrete members in this paper, the linear elastic constitutive model was adopted for concrete, that meaned, concrete was regarded as an elastoplastic material. The linear elastic stress-strain curve of concrete can be expressed by different material constants, and the stress-strain relationship is shown in Formula (1) and Formula (2):

$$
\begin{gathered}
\sigma_{i j}=\frac{E}{1+v} \varepsilon_{i j}+\frac{v E}{(1+v)(1-2 v)} \varepsilon_{k k} \delta_{i j} \\
\varepsilon_{i j}=\frac{1+v}{E} \sigma_{i j}-\frac{v}{E} \sigma_{k k} \delta_{i j}
\end{gathered}
$$

Where, $E$ is elastic modulus of the material, and $v$ is Poisson's ratio of the material. $\varepsilon_{k k}$ is the first invariant of volumetric strain or strain tensor; When $i=j, \sigma_{i j}=0 ; i \neq j, \quad \sigma_{i j}=1$.

The elastic constant relationship is shown in Formula (3):

$$
\lambda_{\mu}=\frac{E \mu}{(1+\mu)(1-2 \mu)}
$$

For $\mathrm{C} 60$ concrete, $\mathrm{E}$ is $3.6 \times 10^{4} \mathrm{MPa}$, then $\lambda_{\mu}$ is $1.0 \times 10^{4} \mathrm{MPa}$.

According to reference [15], the principal tensile stress and principal compressive stress of concrete generated by preloading are shown in Formula (4) and Formula (5) :

$$
\begin{gathered}
\sigma_{t p}=\frac{\sigma_{x}+\sigma_{y}}{2}-\sqrt{\left(\frac{\sigma_{x}-\sigma_{y}}{2}\right)^{2}+\tau^{2}} \\
\sigma_{c p}=\frac{\sigma_{x}+\sigma_{y}}{2}+\sqrt{\left(\frac{\sigma_{x}-\sigma_{y}}{2}\right)^{2}+\tau^{2}}
\end{gathered}
$$

In this paper, according to theory of maximum tensile stress, the failure of concrete was judged, that is, when the tensile stress of a concrete member exceeds the ultimate tensile stress of concrete, brittle failure of concrete will occur. 


\section{(5) Boundary conditions}

Whether the simulation of boundary conditions is accurate or not affects stress analysis results of the joint zone of tower-beam-pier directly. To simulate the boundary conditions, local analysis model was provided with five boundaries on which displacement constraints and force actions were applied as boundary conditions. Consolidation constraints were adopted at bottom of the local model, and internal force loads were applied on left and right boundary surfaces of the main girder and the bridge tower. To facilitate load application, a master node was established at the centroid of each boundary section. Other points on section were coupled with master node, and boundary conditions were applied through master node.

In the actual situation, various working conditions need to be considered about the stress of the bridge. In this paper, internal force combination under maximum cantilever during construction stage was analyzed, and stress distribution and transfer law in the joint zone were studied. The internal forces applied to the boundary were shown in Tab. 1.

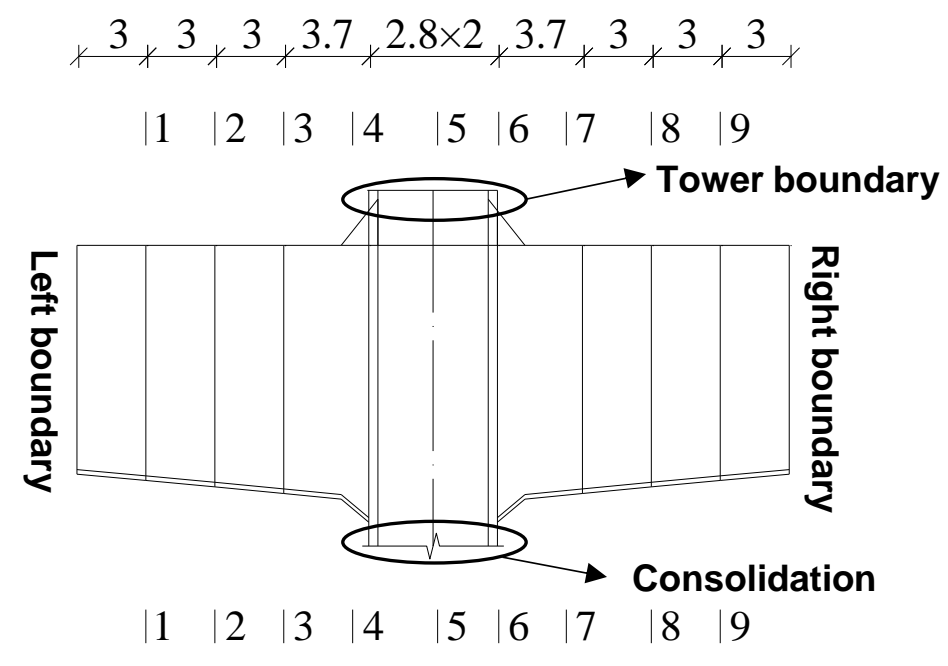

Fig. 3 - Schematic Diagram of Control Section (Unit: $m$ )

Tab. 1: Internal forces of boundary section extracted from the maximum cantilever state in the construction stage

\begin{tabular}{cccc}
\hline Position & Axial force $(\mathrm{kN})$ & Shear force $(\mathrm{kN})$ & Moment $(\mathrm{kN} \cdot \mathrm{m})$ \\
\hline Left boundary & -384987.35 & 4479.11 & 135028.96 \\
Right boundary & -384987.32 & -4479.11 & 135029.16 \\
Tower boundary & -37027.68 & 0 & 0 \\
\hline
\end{tabular}

\section{(6) Model checking}

To study the stress distribution rule of the model, sections at the joints of different beam parts, variable section of the main beam and middle span were taken as the control sections, as shown in Fig. 4, to analyze stress distribution of the control section under maximum cantilever load in the construction stage.

The internal force on boundary section of the local model was extracted, and compared with the internal force of the section extracted by rod system finite element models, the relative error was within $10 \%$, which showed the calculation results of local model were reliable. Internal force checking is shown in Tab. 2. 
Article no. 54

CIVIL

ENGINEERING

JOURNAL

THE CIVIL ENGINEERING JOURNAL 3-2021

Tab. 2: Comparison of internal forces of control section

\begin{tabular}{|c|c|c|c|c|c|c|c|c|c|}
\hline \multirow{2}{*}{$\begin{array}{l}\text { Cross } \\
\text { section }\end{array}$} & \multicolumn{3}{|c|}{ Axial force $(\mathrm{kN})$} & \multicolumn{3}{|c|}{ Shear force $(\mathrm{kN})$} & \multicolumn{3}{|c|}{ Moment $(\mathrm{kN} \cdot \mathrm{m})$} \\
\hline & $\begin{array}{c}\text { Overall } \\
\text { model }\end{array}$ & $\begin{array}{l}\text { Local } \\
\text { model }\end{array}$ & Ratio & $\begin{array}{c}\text { Overall } \\
\text { model }\end{array}$ & $\begin{array}{l}\text { Local } \\
\text { model }\end{array}$ & Ratio & $\begin{array}{c}\text { Overall } \\
\text { model }\end{array}$ & $\begin{array}{l}\text { Local } \\
\text { model }\end{array}$ & Ratio \\
\hline $1-1$ & 395071 & 383564 & 1.03 & 10123 & 10.769 & 0.94 & 110473 & 109379 & 1.01 \\
\hline $5-5$ & 445794 & 464368 & 0.96 & -71626 & -75396 & 0.97 & 90229.7 & -86758 & 1.04 \\
\hline $7-7$ & 430645 & 448588 & 0.96 & -42097 & -40477 & 1.04 & 22119 & 23531 & 0.94 \\
\hline
\end{tabular}

\section{Comparative analysis of stress in the joint zone of tower-beam-pier with different systems}

Because of low stiffness of all-floating system, it is not chosen for cable-stayed bridges [14]. This paper mainly studied the tower-pier consolidation system ("TBCS" for short), rigid frame system ("RFS" for short) and semi-floating system ("SFS" for short). Midas/Civil models of TBCS, RFS and SFS were obtained by modifying restraint mode of tower girder piers. The combination mode of tower girder piers is shown in Table 3. Table 4 shows the boundary internal forces extracted from finite element model of the link system at the bridge completion stage. The finite element analysis of the joint zone of tower-beam-pier of each system in completed bridge state was carried out.

Tab. 3: Boundary conditions of different systems

\begin{tabular}{cccc}
\hline $\begin{array}{c}\text { Cable-stayed bridge } \\
\text { system }\end{array}$ & $\begin{array}{c}\text { Rigid frame } \\
\text { system(RFS) }\end{array}$ & $\begin{array}{c}\text { Tower beam } \\
\text { consolidation } \\
\text { system(TBCS) }\end{array}$ & $\begin{array}{c}\text { Semi-floating } \\
\text { system(SFS) }\end{array}$ \\
\hline $\begin{array}{c}\text { Combination mode } \\
\text { of tower-beam-pier }\end{array}$ & $\begin{array}{c}\text { Consolidation of tower, } \\
\text { beam and pier }\end{array}$ & $\begin{array}{c}\text { Consolidation of } \\
\text { tower and beam, } \\
\text { elastic connection } \\
\text { between tower and } \\
\text { pier }\end{array}$ & $\begin{array}{c}\text { Consolidation of tower } \\
\text { and pier, elastic } \\
\text { connection of pier and } \\
\text { beam }\end{array}$ \\
\hline
\end{tabular}

Tab. 4: Internal forces of boundary section extracted under bridge condition

\begin{tabular}{|c|c|c|c|c|}
\hline $\begin{array}{c}\text { Cable-stayed } \\
\text { bridge system }\end{array}$ & Position & Axial force $(\mathrm{kN})$ & Shear force $(\mathrm{kN})$ & Moment $(\mathrm{kN} \cdot \mathrm{m})$ \\
\hline \multirow{3}{*}{ RFS } & Left of girder & -416564.5 & 4049.1 & 205621.6 \\
\hline & Right of girder & -416564.4 & -4048.3 & 206005.4 \\
\hline & Tower & -57109.6 & -0.5 & 12.0 \\
\hline \multirow{3}{*}{ TBCS } & Left of girder & -359207.9 & 5822.6 & 305078.4 \\
\hline & Right of girder & -35207.9 & -5824.8 & 305158.8 \\
\hline & Tower & -53207.2 & 0 & 27.2 \\
\hline \multirow{3}{*}{ SFS } & Left of girder & -381097.5 & -3551.3 & 427470.4 \\
\hline & Right of girder & -381097.0 & 3549.4 & 427496.8 \\
\hline & Tower & -66778.4 & -0.1 & 19.8 \\
\hline
\end{tabular}




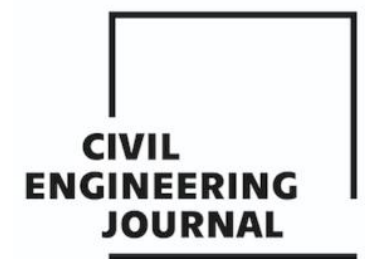

Article no. 54

THE CIVIL ENGINEERING JOURNAL 3-2021

To show stress distribution in the joint zone of tower-beam-pier, stress nephogram of the joint zone was given. According to symmetry of the structure, 1/2 model is selected for analysis, and the results are shown in Figure 4 to Figure 7.

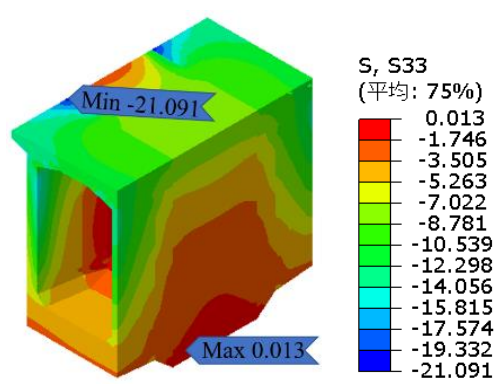

(a) RFS

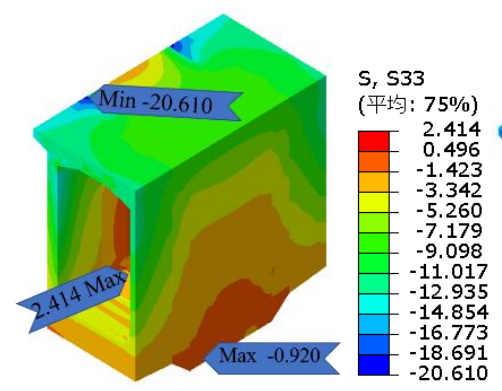

(b) TBCS

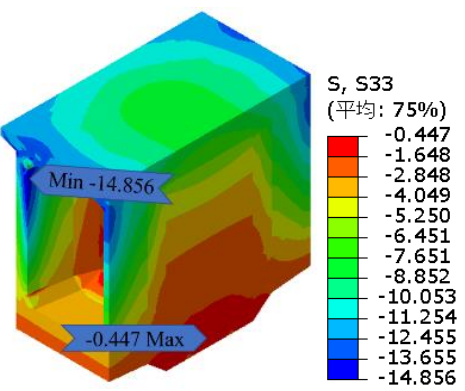

(c) SFS

Fig. 4 - Cloud diagram of principal stress along the bridge

\section{(1) Analysis of normal stress along the bridge}

As shown in Figure 4, in RFS, the maximum tensile stress along the bridge in joint zone of tower girder pier is $0.013 \mathrm{MPa}$. Except for a small amount of tensile stress at top of pier, the whole is dominated by compression. The maximum compressive stress is $-21.091 \mathrm{MPa}$ at tower-beam junction. For TBCS, the concentrated tensile stress of $2.414 \mathrm{MPa}$ occurred at variable section of the beam bottom, and the reinforcement should be strengthened here. A tensile stress of $1.465 \mathrm{MPa}$ appeared at boundary constraint at bottom of the beam. The joint zone of tower-beam-pier was mainly under compression, and the maximum compressive stress of $-20.610 \mathrm{MPa}$ appeared at the junction of tower-beam-pier. In SFS, the maximum normal stress along the bridge was compressive stress, which was $-14.856 \mathrm{MPa}$, and the whole section was under compression. The distribution of normal stress in the three kinds of systems along the bridge was similar, and stress distribution was in the shape of " $П$ ". From the bottom to the top of the beam, the tensile stress decreased to 0 at first, and then compressive stress gradually increased. According to analysis, the normal stress of the tower-beam-pier joint zone along the bridge direction in both RFS and SFS is full-section compression, and the maximum compressive stress in SFS is less than that in RFS. Therefore, from the perspective of stress analysis, stress in the joint zone in SFS is more reasonable than that in the other two systems. The normal stress of tower-beam-pier joint zone along bridge direction in RFS is less than that in TBCS.
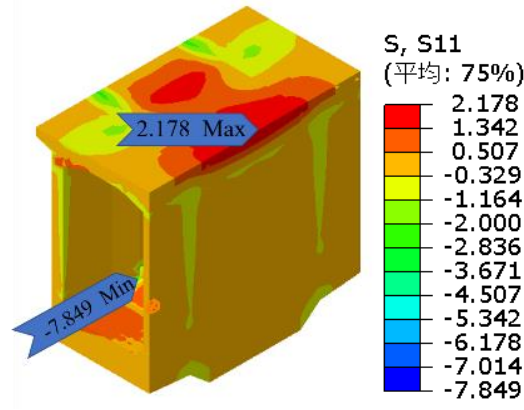

(a) RFS

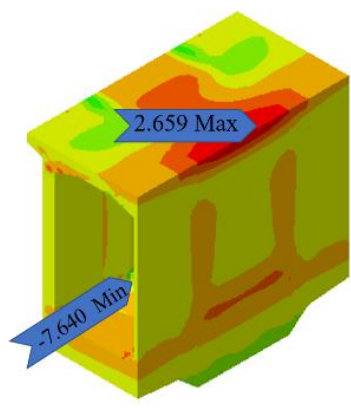

(b) TBCS

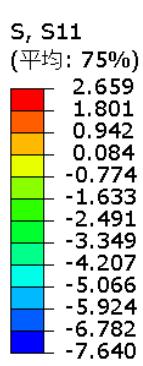

$-7.640$

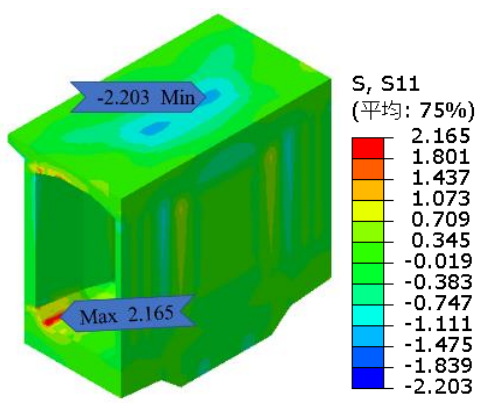

(c) SFS

Fig. 5 - Cloud diagram of transverse principal stress

(2) Analysis of normal stress in transverse direction 


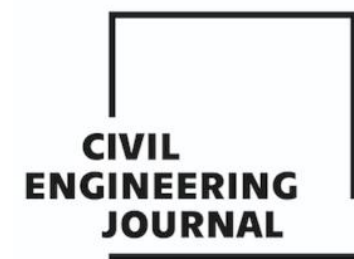

Article no. 54

THE CIVIL ENGINEERING JOURNAL 3-2021

As shown in Figure 5, in RFS, there was a large tensile stress at top plate of the towerbeam-pier joint zone, with value of $2.178 \mathrm{MPa}$, which was mainly distributed at inner edge of the tower-beam contact and center of the top of the midspan beam, which degenerated from the center outward. The maximum compressive stress was -7.849MPa. In TBCS, distribution of normal stress in the joint zone was similar to that in RFS. The maximum tensile stress in the roof was 2.202 $\mathrm{MPa}$, and the concentrated tensile stress at the intersection point of the box girder was 2.659MPa. In SFS, there was a concentrated tensile stress at the chamfering angle between web and bottom plate in tower-beam-pier joint zone, and the value was 2.160MPa. There was concentrated compressive stress at boundary constraint at bottom of the box girder and top plate of box chamber, whose maximum value was $-2.200 \mathrm{MPa}$, which decreased and diverged around. The transverse normal stress in joint zone of the three systems was less than the allowable value of C60 ultimate compressive stress. According to analysis, in SFS, normal stress in joint zone of tower-beam-pier is the least, and stress in the joint zone is more reasonable than the other two systems.

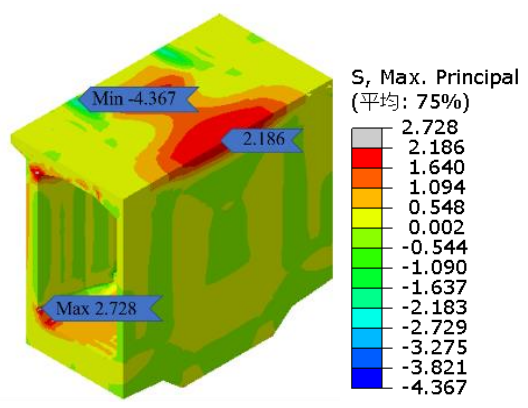

(a) RFS

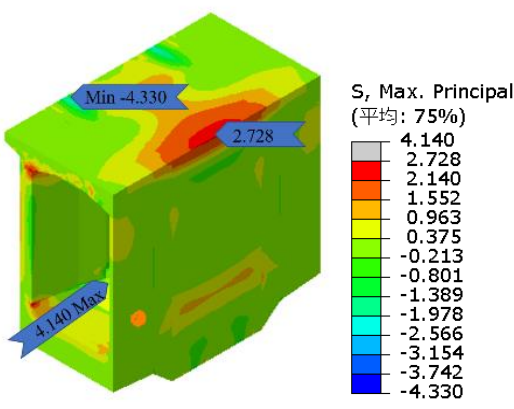

(b) TBCS

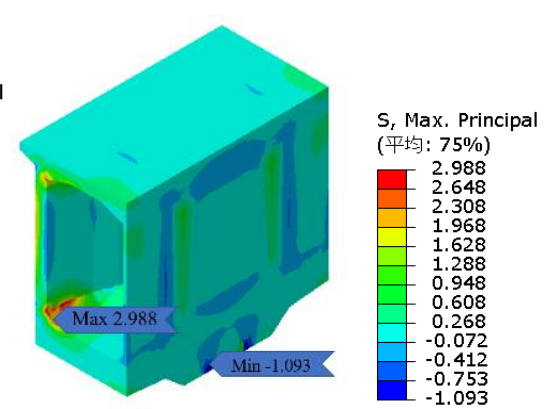

(c) SFS

Fig. 6 - Cloud diagram of the first principal stress

\section{(3) Analysis of Principal stress}

As shown in Figure 6, in RFS, the first principal stress in joint zone of the tower-beam-pier was mainly compressive stress, and the maximum compressive stress occurred at the junction between the lower edge of the box girder roof and the tower, with a value of $-4.367 \mathrm{MPa}$. Tensile stress was mainly distributed in center of the beam roof and the inner edge of the junction between the tower and the top surface of the beam. The maximum tensile stress was $2.186 \mathrm{MPa}$, and the compressive stress was $2.728 \mathrm{MPa}$ at the chamfering between the web and the bottom plate. The distribution of the first principal stress of RFS was similar to that of TBCS. The maximum compressive stress was $-4.33 \mathrm{MPa}$, the maximum tensile stress of the roof was $2.200 \mathrm{MPa}$, and the concentrated compressive stress in the chamfering of the web and the bottom plate was 4.140MPa. In SFS, the first principal stress in the bonding zone was mainly compressive stress. In addition to the concentrated tensile stress of $2.988 \mathrm{MPa}$ at the chamber of the web and the bottom plate, the stress distribution of the roof, bottom plate and the web was uniform. The maximum compressive stress appeared at the boundary constraint was at bottom of the box beam, and the maximum compressive stress was $-4.18 \mathrm{MPa}$, which didn't exceed the strength limit of C60 concrete. 


\section{$\prod_{\text {CIVIL }}$ JOURNAL}

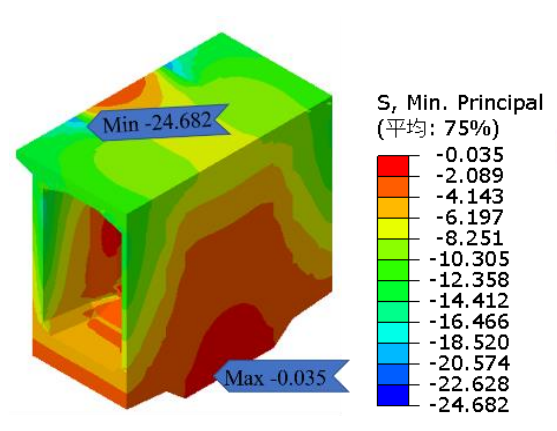

(a) RFS

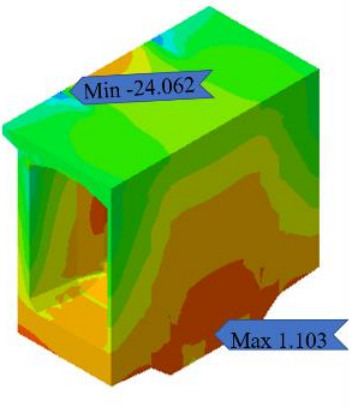

(b) TBCS

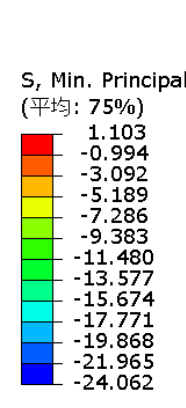

4.062

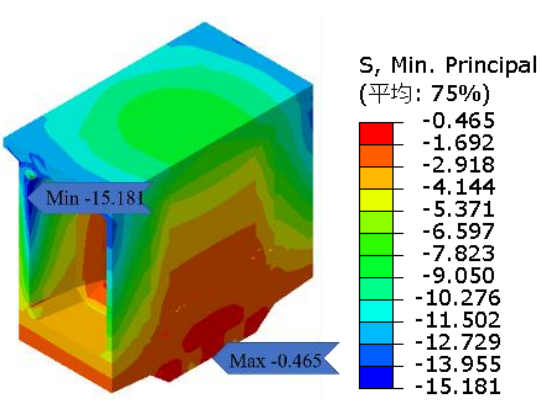

(c) SFS

Article no. 54

THE CIVIL ENGINEERING JOURNAL 3-2021

Fig. 7 - Cloud diagram of the third principal stress

As can be seen from Figure 7, the third principal stress in bonding zone of the three systems was dominated by compression. The maximum compressive stress in RFS was 24.682MPa, 24.062 MPa in tower and beam consolidation system, and $-15.181 \mathrm{MPa}$ in SFS. The distribution of the first principal stress nephogram of RFS and TBCS was similar to that of the transverse bridge normal stress nephogram. There was a concentrated tensile stress of $1.103 \mathrm{MPa}$ at boundary constraint at bottom of the box girder in consolidation system. According to analysis, in case of the SFS, the transverse normal stress in junction zone of the tower beam pier is the smallest, and the force in the junction zone is more reasonable than the other two systems.

Figure 8 showed the vertical displacement of the local model. The variation range of the deflection in RFS was 0 to $2.67 \mathrm{~mm}$. The deflection varied between $-0.19 \mathrm{~mm}$ and $-2.93 \mathrm{~mm}$ in the consolidation system of tower beam girder. The deflection range of SFS was $-0.13 \mathrm{~mm}$ to $-2.89 \mathrm{~mm}$. Compared with the other two systems, the displacement generated by RFS under the action of boundary load was the smallest, and the maximum displacement occurred at the boundary section, with a value of $2.67 \mathrm{~mm}$.

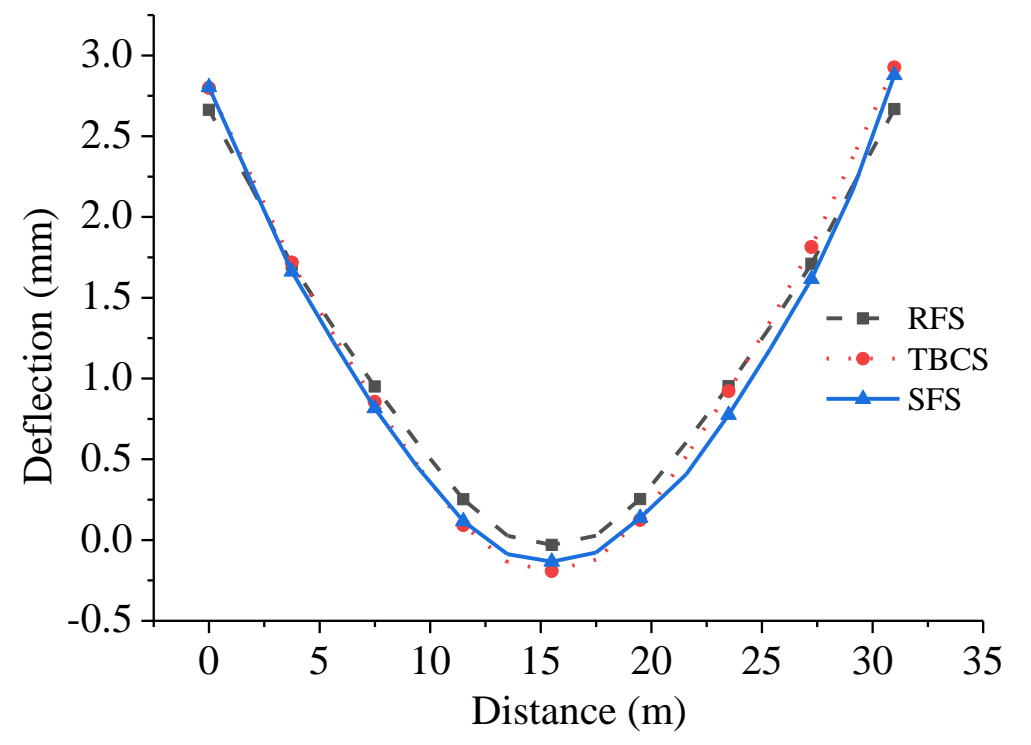

Fig. 8 - Deflection curve of main girder roof 


\section{CONCLUSION}

Through the local calculation and analysis of the consolidation zone of tower-beam-pier of a cable-stayed bridge, comparison of stress state of the joint zone of tower-beam of a cable-stayed bridge under different systems, the following conclusions can be drawn.

(1) In SFS and RFS, joint zone of tower-beam-pier is subjected to compression along the full section of the bridge. The maximum compressive stress in the joint zone was $-14.856 \mathrm{MPa}$ in SFS, $-21.091 \mathrm{MPa}$ in RFS, and -20.610MPa in TBCS.

(2) In SFS, the maximum transverse tensile stress in bonding zone was $2.165 \mathrm{MPa}$; when RFS was used, the maximum transverse tensile stress in the joint zone was $2.178 \mathrm{MPa}$. The maximum tensile stress in the cross-bridge direction of the junction zone was $2.659 \mathrm{MPa}$ when TBCS was used. Compared with RFS and TBCS, stress distribution in bonding zone of SFS is more reasonable.

(3) The first principal stress in bonding zone of the three systems is small, and the concentrated tensile stress appears at the chamfer of the web and the bottom plate, where steel bars should be added. Compared with RFS and TBCS, SFS has no tensile stress at the pier top, and the stress distribution is more reasonable.

(4) In SFS and RFS, the third principal stress in joint zone is compressive stress. In TBCS, there was a concentrated tensile stress of $1.103 \mathrm{MPa}$ at boundary constraint at the bottom of the box girder. The maximum compressive stress in joint zone along the bridge was $-15.181 \mathrm{MPa}$ in SFS, -24.682MPa in RFS and -24.062MPa in TBCS.

(5)

In RFS, deflection of the main beam under action of load was the smallest, and the maximum displacement occurs at the boundary section, and the value was only $2.668 \mathrm{~mm}$.

\section{ACKNOWLEDGEMENTS}

This paper is supported by the Anyang Science and Technology Plan Project (2020) (grant number: 251) and Anyang Institute of Technology Research and Cultivation Fund (grant number: YPY2020021).

\section{REFERENCES}

[1] Yu Yanxia, Wang Dezhi. Design of the 95+125 m Asymmetric Single Tower Part Cable-Stayed Bridge of Fuzhou-Xiamen High-speed Railway [J]. Railway Standard Design,2020,64(S1):147-151.

[2] Wen Wangqing, Li Diping, Yan Aiguo, Huang Naxin. Study on Structural System of $3 \times 340 \mathrm{~m}$ Multitower Cable-Stayed Bridge [J]. Railway Standard Design,2020,64(03):86-90.

[3] Pan Xiangwen. Study on Mechanical Properties of High-speed Railway Cable-stayed Bridges with Short Tower [J/OL]. Railway standard design :1-6[2021-03-16]

[4] DENG Jiangtao. Analysis and Verification of Local Stress in Consolidation Section of Low Tower Cable-stayed Bridge Pier and Tower Beam of High-speed Railway [J]. Railway Standard Design,2016,60(06):43-48.

[5] Peiheng Long, Zechao Lu, Suwei Hou, Chiyu Jiao, Guangda Zhang. Research on Stress Analysis of Consolidation Area of Tower Pier of Steel-composite Composite Cable-stayed Bridge [J]. Chinese and Foreign Highway,2018,38(01):80-83.

[6] Yu Lusong, Zhu Dongsheng. Local Stress Analysis of Consolidation Point of Pier of Partly CableStayed Bridge [J]. Bridge Construction, 2008(01):54-57.

[7] Song Jun, Zhou Jianting, Chen Zengshun. Local Analysis of Consolidation Section of Pier of Cablestayed Bridge Based on Submodel Method [J]. Journal of Chongqing Jiaotong University (Natural Science),2013,32(03):379-384. 
[8] HU Yuliu. Model Test Study on Consolidation Zone of Main Bridge Pier of Changmen Bridge [J]. Bridge Construction,2018,48(02):72-76.

[9] Wang Ziwen, Xu Shiwen, Deng Lu, Liu Binghui, Guo Jinlong. Model test on tower-beam bonding zone of variable cross-section elliptic single-tower cable-stayed bridge [J]. Chinese and foreign highway,2019,39(04):83-88.

[10] Shangguan Ping, Fang Zhenzheng, Zhuo Weidong. Journal of Fuzhou University (Natural Science Edition), 1999(03):21-24. (in Chinese)

[11] Dai Gonglian, Su Miao. Experimental Research and Numerical Analysis on the Structure of Tower Girder of High-speed Railway Trough-beam Cable-stayed Bridge [J]. Journal of the China Railway Society,2015,37(03):85-92.

[12] ZHOU Min, DAI Gonglian, SU Miao. Numerical Simulation of Stress in Consolidation Zone of Tower Pier of Trough-section Cable-Stayed Bridge [J]. Journal of Railway Science and Engineering,2013,10(04):35-40.

[13] Li Bo, Wang Lifeng, Chen Xinpei, Wang Erqiang. Spatial Stress Analysis of 0 \# Block of Short Tower Cable-Stayed Bridge [J]. China Highway and Wai Highway,2014,34(03):127-130.

[14] Jiang Rongfeng. Stress Analysis of Consolidation Zone of Single Tower Cable-stayed Bridge with Channel Section [D]. Central South University, 2013.

[15] Zhongjiao Highway Planning and Design Institute. Code for Design of Highway Reinforced Concrete Prestressed Concrete Bridges and Culverts (JTG D62-2018). People's Communications Publishing House, Beijing, China, 2018. 